\title{
Research on the Financial Risk Control and Preventive Measures of Small Micro Enterprise of Our Country
}

\author{
Fu Huilian \\ Wuhan Polytechnic
}

Keywords: small micro enterprises; financial risks; risk control; preventive measures

\begin{abstract}
As the most innovative growth in our national economy, the small micro enterprises play an important role in the prosperous market economy, boosting technological innovation, promoting employment and maintaining social stability, etc. It is vital practical significance for continuing to promote the health development of small micro enterprises that we prevent the financial risks of small micro enterprises. Starting from the summary of the small micro enterprise financial risks, this paper analyses its causes and puts forward some measures of control and prevention .It will be helpful to the development of small enterprises in our country.
\end{abstract}

\section{Small Micro Enterprise Financial Risk Problem}

1.The Judging Standards of Small Micro Enterprise in Our Country

The nature of small enterprises in China belong to the private business and individually-owned business. It is an umbrella name of small and micro enterprises, and it is a kind of classification of small and medium-sized enterprises. Small and medium-sized enterprises can be divided into medium enterprises, small enterprises, mini enterprises. The judging standards of small micro enterprises as follows: Industrial enterprises. The annual taxable income shall not exceed 300000 yuan (RMB, same below) and no more than 100 workers. The total assets are less than 30 million yuan; Other enterprises, the annual taxable income shall not exceed 300000 yuan and no more than 80 workers. The total assets are less than 10 million yuan. Small micro enterprises are important parts of modern market economy. They have a wide range of social and economic base. They are of great significance to the development of national economy.

2.The Financial Risk of Small Micro Enterprise

Financial risk refers to that the risk of loss and other financial conditions not going as planned in a certain period,which is caused by the enterprises internal financial structure unreasonable and the status of the financing improper deviation with expected planning due to the influence of many factors in the process of enterprises handling the relevant financial affairs.

Enterprise financial activities are generally divided into four parts, financing, investment, operation and benefits. Accordingly, the financial risks of the enterprise also exist among them.

(1)The Financing Risk. Raising money is an important measure of the development of an enterprise. In the market economy, the competition between enterprises, management decision-making, the change of capital supply and demand, profitability, etc., all can affect enterprise financing risk. "Improper selection of financing ways may cause the financial risk of enterprises".

(2)The Investment Risk. Investment risk refers to the uncertainty of enterprise investment earnings. Their decision-making errors are the main reasons. Because of the difference of capital turnover time and amount difference, that lead to money recycling risks.

(3)The Capital Operation Risk. In normal business activities, enterprises tend to reserve some products. However, these products on the one hand, waste the enterprise funds, on the other hand also can increase the management cost. In the process of enterprise management, large amount of credit products also poses risks to the corporate finance function normally.

(4)The Risk of Income Distribution. Income distribution will affect the operation and management of the enterprise, the income distribution is the last link of financial cycle. Income distribution is divided into retained earnings and dividend distribution. Retained earnings is used to 
expand the scale of enterprise. The fast development of enterprise leads to the need of acquiring a large number of assets. High profits will affect the Stock value of enterprise.

Through the above analysis, we can find the enterprise's financial risk generally has these features. Fristly, the objectivity. Enterprise financial risk exists objectively and people can't eliminate it. Only fully using all kinds of technical advantage to make scientific decisions, can people reduce the enterprise financial risk. Secondly, the correlation. The productive status of enterprise and financial risk influence each other. The benign operation in enterprise's finance is the foundation of all business activities. "Once the enterprise's financial management happens risk, it often causes many difficulties in enterprise management, and even bankruptcy". Thirdly, the compatibility. Enterprise financial operations embody the coexist of returns and risks, and positively related to both. The charactes of enterprise financial risk require that people must fully grasp the financial risk in the process of the enterprise operation.

\section{The Causes Analysis of Financial Risk of Small Micro Enterprises in Our Country}

1. The capital structures are not reasonable in small micro enterprises.

Currently, the capital market in China is in developing stage. Due to its development is relatively slow, thus the small micro enterprise financing process is a lack of systematic and standardized management in our country. At present, before financing, there are a lot of small micro enterprises all have no full understanding with the investigation to capital markets. And in the actual process of financing , they are too blind and go with the flow, that makes the enterprise's capital structure unreasonable, furthermore lead to the financial risks of the small micro enterprise are too high, resulting in the increase of debt financing ratio and debt service pressure. All these bring huge hidden troubles to the stable development of the small micro enterprise.

2.The circulating fund of small micro enterprises is not sufficient.

Embodied in the backlog of inventory occupies a large of working capital in small micro enterprises, so the capital operation is relatively limited. High inventory, for a long time, will also brings some losses. All these problems are important factors which lead to financial risk of enterprise. In addition, it is not sound that the accounts receivable management mechanisms in many small micro enterprises, so,it can also lead to inadequate liquidity, furthermore cause all sorts of enterprise financial risk.

3.The variety and complexity of external environment.

The external environment pressures of small micro enterprises mainly include the market competition, changes in the international market, and the national policy constraints,etc. These factors which bring pressures to small micro enterprises are of unpredictability. It is weak that the small micro enterprise owns capital, technology, and the reserve of talents. Its market position is dangerous. So the changes in the development of the market will be great effects on the financial management of small micro enterprises.At last, some disadvantages such as the weakness of financial management measures, poor predictability and slow response will be displayed.

4.It is weak that the capacities of enterprise leaders and financial managers identifying and disposing risks, and the risk information they grasp is one-sided and incomplete.

These weaknesses lead to enterprise can not establish a more scientific, perfect and effective financial risk management mechanism. Thus, in a way, it greatly enhances the probability of enterprise financial risk, and may eventually leads to a severe financial crisis, even bankruptcy of enterprises.

\section{The Innovative Strategy of Guarding Against Enterprise Financial Risk}

1. Optimizing the small micro enterprise capital structure.

We should reasonably adjust the small micro enterprise financial structure and corporate debt ratio. Looking for a way realize the benign circulation of capital structure to study the problem of capital structure. Starting from establishing reasonable capital structure, with high benefit and appropriate risk as foothold, we need have a reasonable dynamic combination to the enterprise 
capital structure, to accomplish a new reasonable capital structure.

2. Managing scientifically the small micro enterprise current assets.

Solving the problem of inventory backlog and speeding up the capital operation. We should improve the mechanism of accounts receivable management, and recover accounts receivable in time, in order to preventing the shortage of cash.

3. Improving the scientific level of financial decision-making.

First of all, we should pay attention to financial performance evaluation. Actively improving the performance evaluation, earnestly implementing the financial risk liability, timely introducing the mechanism of enterprise risk into the interior of enterprise development. We could put the performance evaluation and salary system combining and motivate employees better to guard against risks; Second, seriously do a good job in the process of financial risk control. According to the development of the enterprise financial status, we could completes the beforehand control, matter controls, afterwards controls, actively develop coping strategies, the risk, the lessons as far as possible to reduce financial risk caused by the damage.

4. Perfecting the early warning mechanism of identifying and disposing enterprise financial risks.

First, strengthening the awareness of risk early warning. The financial risks exist in all aspects of financial management work, and each work error link may bring to the enterprise financial risk. So we need to strengthen this awareness; Second, improving the system of internal control. This can not only ensure reliability and safety of enterprises' financial data, but also , at the same time, it can provide first-hand data for financial early warning. What is more, it will make enterprise financial departments timely grasp the financial information and make corresponding countermeasures; Again, paying attention to the integration of qualitative methods and quantitative methods, to ensure the accuracy of the financial risk early warning.

\section{Conclusion}

The prevention and management of financial risk in small micro enterprises are important contents of modern enterprise financial management. So we should attach great importance to them and take effective measures to improve the ability of prevention to achieve the stable and healthy rapid development of the enterprise. At the same time, we should also focus on the adjustments and changes of national policies, market development, market supply and demand, and all cost factors such as the external environment factors. We also need to grasp the enterprise internal production situation and financial conditions. At last, we consider them comprehensively according to the enterprise environment changes. Only in these ways can we timely take correct and reasonable measures to effectively control the financial risks.

\section{References}

[1] Qiang Qinqin. Small and Medium-Sized Enterprise Financial Risk and Its Circumvention [J] .CO-operative Economy \& Science, 2016,1

[2] Lin Lina. Problem of Small Micro Enterprise Financial Management in Our Country and the Suggestion [J] . Modern Economic Information,2015,12

[3] Gao Junhua. Analyzing Enterprise Financial Risk Prevention and Control Measures[J]. Chinese Business, 2015,1

[4] Li Gang. Analyzing Enterprise Financial Risk Prevention and Control Measures [J] . Modern Economic Information,2014.11

[5] Zhou Lei. Analyzing Enterprise Financial Risk Formation Reasons and Prevention Strategies [J] . Guide to Business,2015,12

[6] Liu Haijuan. Discussion on the Small and Medium-Sized Enterprise Financial Risk Control and 
Prevention in Our Country. [ J ] . China Business \& Trade,2014,9 